\title{
New Trend in Textile Coloration Using Microwave Irradiation
}

\author{
N. S. Elshemy* and K. Haggag \\ Textile Research Industrial Division (TRID), Dyeing, Printing and Textile Intermediate \\ Department (DPTID), National Research Centre (NRC, Scopus affiliation ID \\ 60014618), El-Behouth St. (former El-Tahrir str.), Dokki, P.O. 12622, Giza, Egypt
}

\begin{abstract}
TN A MILLENNIAL world we need new manufacturing technologies if we are to meet the demands of a new generation of consumers. Microwave technologies facilitate that evaluation, let's investigate how microwave technology is disrupting every sector of textile coloration. The purpose of this review is to evaluate the current status of microwave processing technology, and to find out applications of unique properties leading to replacement of conventional techniques due to reduced cost, energy, and time, and enhance the properties of the different fabric for end use. Furthermore, we will focus on the future of textile coloration and developments employing the microwave processing.
\end{abstract}

\section{Introduction}

Textile dyeing industry mainly employs natural dyes as a replacement for synthetic dyes, because of their lower price, higher brightness, available multiple colors, and superior fastness properties. Everyone has forgotten what damage caused by these dyes, for example, toxicity, carcinogenicity, and non-biodegradability $[1,2]$. In addition, the synthetic dyes cause environmental and water pollution. Currently, textile industry seeks to reduce the toxicity of colorants including dyes and pigments and to stop the production of potentially harmful colorants to the environment and humans. For these reasons, there is a main target to return to natural dyes for textiles coloration due to lack of toxicity, environmentally friendly, no damage to health, no pollution rises to neither the environment nor water [3-5].

Many researchers are interested in finding out novel technologies to achieve quality, time saving, reduce energy consumption and eco-friendly processing [6-10]. On When interacting materials have dielectric properties should be of these new technologies is known as "microwave technology" which could be used in different textile processes such as finishing, dyeing, printing and wet processes while achieving the targets mentioned above [11-13]. One of the main advantages provided by microwave heating is homogenized, as the heating is uniformly distributed in homogeneous manner and in all directions, while in the classical method, heating occurs from the outside to the inside of the heated system, which results in heterogeneity in the thermal distribution $[14,15]$. This leads to speed up heating when compared to the conventional way, so the microwave reduces power consumption and reduce operational time $[16,17]$.

In addition, energy transfer at a molecular level can have some additional advantages, which known as "volumetric heating". Another advantage, Microwave characteristic by used "selective heating" of materials. The ability of the microwaves to interact with materials and transfer energy affects by molecular structure. When interact materials have dielectric properties, couple with the higher loss material will selectively by microwaves $[18,19]$. This phenomenon of selective heating can be applied for a number of purposes. When classical heating is applied, considerable time and energy is consumed to heating up the interface by conduction through the substrates. While, when using microwaves, the joint interface can be heated in-situ by incorporating a higher loss material at the interface [20]. In manifold stage materials, some stages may couple more easily with microwaves. Consequently, it may be possible to produce materials with new or individual microstructures 
by selectively heating distinct stage. Microwaves can able to initiate chemical reactions through selective heating of reactants; so, new materials may be formed, which is not possible in classical processing [21-23].

Many researchers' assume to investigate the ability to use microwaves for the wide range of materials, as ceramics, polymers, composites (ceramic and polymer matrix), powders, and minerals. Microwaves have also been investigated in a wide range of plasma processes (surface treatment, infiltration of chemical vapor, powder processing), chemical synthesis and processing, and waste treatment. Although, the great effort that has been spends in development of microwave process, there has been little industrial application till now, with most of the effort still in the laboratory stage. Some of the more important problems that have prevented industrial apply. The main problems have related with microwave processing, puts the user cation of microwave processing are: i) equipment cost, ii) limited applicability, iii) variation in dielectric properties with temperature; and iv) the ingrained inefficiency of electric power.

This review discussed a broad range of microwave applications. This will help to identify promising applications for future development and will help processors to avoid potential risks. This review has two targets; the first is to produce the knowledge required for a basic understand, advantages and limitations of microwave processing technology. Examples of successful applications are going to be given to assist producing connected understanding of the conditions necessary for achievements. The second goal is to identify analysis techniques and development that may be crucial toward the improvement of textile coloration by using microwave irradiation.

\section{Microwave Technology}

The field of radio frequency (RF) and microwave generally covers the behavior of alternating current signals with frequencies in the range of $100 \mathrm{MHz}(1 \mathrm{MHz}=106 \mathrm{~Hz})$ to $1000 \mathrm{GHz}$ $(1 \mathrm{GHz}=109 \mathrm{~Hz})$. RF frequencies range from very high frequency (VHF) $(30-300 \mathrm{MHz})$ to ultra-high frequency (UHF) (300-3000 MHz), while the term microwave is typically used for frequencies between 3 and $300 \mathrm{GHz}$, with a corresponding electrical wavelength between $\lambda=\mathrm{c} / \mathrm{f}=10 \mathrm{~cm}$ and $\lambda=1 \mathrm{~mm}$, respectively. Signals with wavelengths on the order of millimeters are often referred to J. Text. Color. Polym. Sci. 16, No. 1 (2019) as millimeter waves. Figure 1 shows the location of the RF and microwave frequency bands in the electromagnetic spectrum [24]. The word "microwave" clarifies the microwave techniques and concepts used as well as the frequencies range. Microwave radiation spread in matter in the same way that the light waves spreads: they are reflected by metals, absorbed by some dielectric material, and implemented through other materials without any significant loss, as water, carbon, foods that contain large amounts of water, and some organic solvent which have the ability to absorb microwave radiation, while ceramic, quartz and most thermoplastic material absorb microwave irradiation slightly [25].

Because the complication of microwave interactions with materials, the successful application of microwave processing, put the user on a heavier order to understand the difference between microwave technique and classical heating. However, wise application may lead to greater advantages than expected. Materials processors are becoming more advanced at textile material to the manufacturing process in order to take full advantages to use the possibilities of microwaves as a new heating source $[25,26]$.

High-frequency heating really started once engineers operating on short-wave transmitters narrowed artificial fevers. The great virtues of this heat type area unit as follows: the heat is generated directly within the object itself; no transfer of heat is concerned. Associated apparatus would like not be heated. The surfaces of the material needn>t be affected. The textile industry work with the instrumentation has cooler operating conditions. No gases are concerned and so the probability of unsound surfaces is eliminated. The materials are often heated from the inside-out. Finally, objects of unusual size or shape are often heated $[27,28]$

Microwaves were first dominated and used during the Second World War as a very important component of radar systems. The advantages of radio-frequency heating were introduced earlier, the interest of microwaves in the heating materials was first discovered in 1946, and then Raytheon introduced the first microwave to the market in 1952 During the last two decades, the microwave has become a present technology, with more than 60 million homes having one. Although this long history and widely use, there still remains a great deal it has not been understood about microwaves [29]. 
The main problems have related to the user who lack the understanding of the essential interaction mechanism that occur between material and microwave irradiation, from the equipment design to meet the needs of a specific application, and the inherent limitations (including cost) of microwaves as a processing methodology. The incomplete understanding of the basic interactions occur between materials and microwaves and also incomplete data base, hindered the specialists of microwave technology to test their theories and models and facing some problem to provide guidance in designing proper systems for practical use [29-31].

\section{Microwave interaction}

When various materials exposed to electrical field of the microwave irradiation, different response can take place. In the material electrons usually move freely which lead to the electric field and hence electric current. These materials have the ability to heat up by the electrons flow through resistive heating, except in the superconductor materials. However, metallic conductors can reflect microwave radiation; therefore these conductors are not effectively heated by microwave. In this case, the electrons of these materials cannot move freely, insulators, so electronic reorientation or distortions of induced or permanent dipoles are considered as heating source. Microwave radiation is based on dielectric heating phenomenon, some polar liquids and solids have ability to absorb and convert microwave energy into heat. In this context, a significant property is the quality of the dipoles by either ionic conductivity or dipolar polarization and therefore the ability to orient them in keeping with the direction of the electrical field. The orientation of the dipoles depends on the magnitude and the electrical field direction. Through rotation, molecules that have a permanent dipole moment can align themselves completely or at least partly, with the direction of the field. Therefore, energy is lost in the variety of heat through molecular friction and dielectric loss. The amount of heat produced by this method is directly associated with the aptitude of the matrix to align itself with the frequency of the applied of electric field. If the dipole does not have enough time to realign, or reorient too rapidly with the applied field, no heating occurs [32].

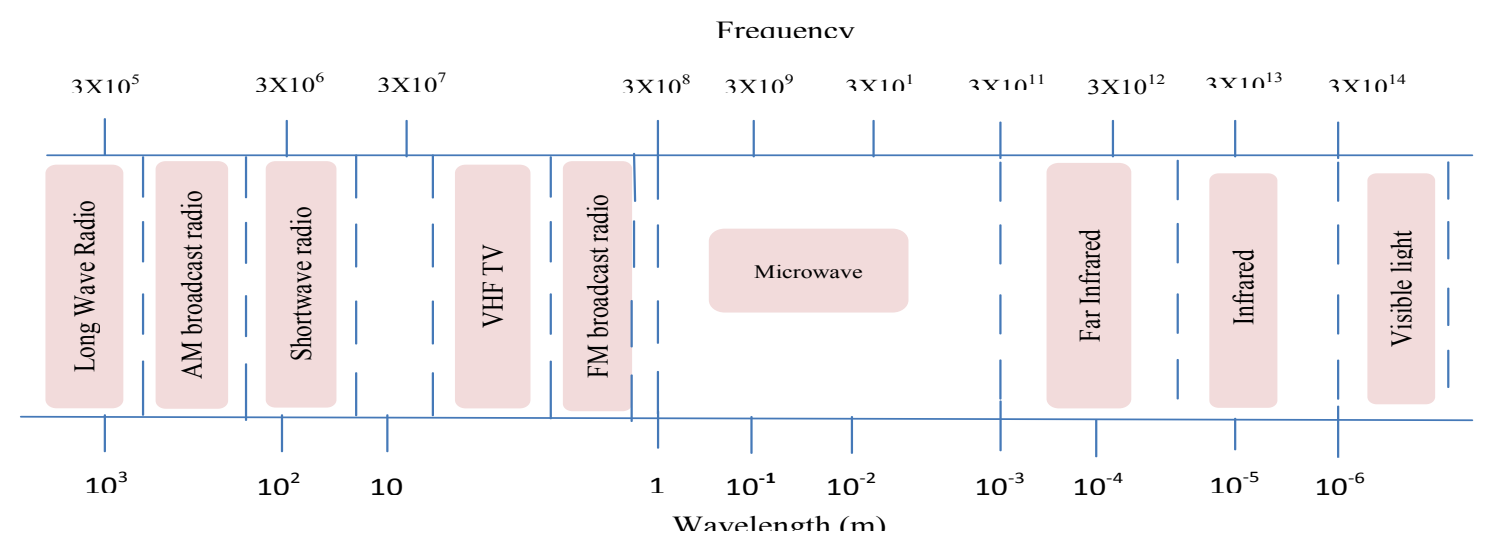

$\begin{array}{cccc}\text { Typical Frequencies } & & \text { Approximate Band Designations } \\ \text { AM broadcast band } & 535-1605 \mathrm{kHz} & \text { Medium frequency } & 300 \mathrm{kHz}-3 \mathrm{MHz} \\ \text { Short wave radio band } & 3-30 \mathrm{MHz} & \begin{array}{c}\text { High frequency (HF) } \\ \text { Very high frequency (VHF) }\end{array} & 30 \mathrm{MHz}-300 \mathrm{MHz} \\ \text { FM broadcast band } & 88-108 \mathrm{MHz} & \text { Ultra-high frequency (UHF) } & 300 \mathrm{MHz}-3 \mathrm{GHz} \\ \text { VHF TV (2-4) } & 54-72 \mathrm{MHz} & \text { L band } & 1-2 \mathrm{GHz} \\ \text { VHF TV (5-6) } & 76-88 \mathrm{MHz} & \text { S band } & 2-4 \mathrm{GHz} \\ \text { UHF TV (7-13) } & 174-216 \mathrm{MHz} & \mathrm{C} \text { band } & 4-8 \mathrm{GHz} \\ \text { UHF TV (14-83) } & 470-890 \mathrm{MHz} & \text { X band Ku band } & 8-12 \mathrm{GHz} \\ \text { US cellular telephone } & 824-849 \mathrm{MHz} & \text { K band } & 12-18 \mathrm{GHz} \\ \text { European GSM cellular } & 869-894 \mathrm{MHz} & \text { Ka band } & 18-26 \mathrm{GHz} \\ & 880-915 \mathrm{MHz} & \text { U band } & 26-40 \mathrm{GHz} \\ \text { GPS } & 925-960 \mathrm{MHz} & \text { V band } & 40-60 \mathrm{GHz} \\ & 1575.42 \mathrm{MHz} & \text { E band } & 50-75 \mathrm{GHz} \\ \text { Microwave Oven } & 1227.60 \mathrm{MHz} & \text { W band } & 60-90 \mathrm{GHz} \\ \text { US DBS } & 2.45 \mathrm{GHz} & \text { F band } & 75-110 \mathrm{GHz} \\ \text { US ISM } & 11.7-12.5 \mathrm{GHz} & & 90-140 \mathrm{GHz}\end{array}$

Fig. 1. The location of the RF and microwave frequency bands in the electromagnetic spectrum. 
Microwave processing depend on to find a material that have able to polarize and whose dipoles will reorient rapidly in response to change the strength of electric field. Fortunately, many materials meet these need, therefore they are candidate materials for microwave process. However, if these materials have poor thermal conductivity, heat does not rapidly dissipate into the encompassing regions of the materials once a district within the solid becomes hot. This difficulty is combined, because the dielectric loss often times will increase dramatically as the temperature will increase. Thus, the hot region becomes even hotter, sometimes resulting in local melting. These "hot spots" are a major difficult and have led to the utilization of hybrid systems, combining microwave heating with other heating sources to reduce uneven heating [33].

When use classical heating source, such as, Oil bath, for organic synthesis, heat will take place from the surface into the interior of the specimen, the reaction will be slow and ineffective for transferring energy into the system, because it depends on the thermal conductivity of the materials that can be penetrated, and the result is the reaction vessel have higher temperature than that of the reaction mixture. On contrary, microwave produce effective internal heating (in core volumetric heating) by direct coupling of microwave energy with the solvents, reagents or catalysts that are present in the reaction mixture [34].

Microwave Fundamentals

The range of all possible frequencies of electromagnetic radiation called the "electromagnetic spectrum". The electromagnetic spectrum of an object is the characteristic distribution of electromagnetic radiation released or absorbed by that specific object.

The electromagnetic spectrum ranged from modern radio communication "low frequencies" to gamma radiation at the short wavelength (high frequency), herewith covering wavelengths from thousands of kilometers down to a fraction of the atom size [31]. Electromagnetic waves could be absorbed and output edit units of energy called photons. The photon energy depends on the wavelength and wave frequency. The photon energy emitted by microwave is 0.125 watt and this value is less than the required energy needed for chemical bonds. Therefore, the microwave radiation cannot affect the installation of the molecule directly, but can change of the electronic structure of atoms $[35,36]$.

TABLE 1. Main interactions of electromagnetic radiation with matter [35].

\begin{tabular}{ll}
\hline Region of the spectrum & Main interaction with matter \\
\hline Radio & $\begin{array}{l}\text { Collective oscillation of charge carriers in bulk material (plasma } \\
\text { oscillation). An example would be the oscillation of the electrons } \\
\text { in an antenna. } \\
\text { Plasma oscillation, molecular rotation. } \\
\text { Microwave }\end{array}$ \\
Near infrared & $\begin{array}{l}\text { Molecular vibration, plasma oscillation (in metals only). } \\
\text { Molecular electron excitation (including pigment molecules found } \\
\text { Visible }\end{array}$ \\
Ultraviolet & $\begin{array}{l}\text { Excitation of molecular and atomic valence electrons, including } \\
\text { ejection of the electrons (photoelectric effect }\end{array}$ \\
X-rays & $\begin{array}{l}\text { Excitation and ejection of core atomic electrons, Compton } \\
\text { scattering (for low atomic numbers). }\end{array}$ \\
Energetic ejection of core electrons in heavy elements, Compton \\
Gamma rays
\end{tabular}




\section{Microwave generators}

It can't be discussed the microwave generators without highlighting two major developments: 1) Space charge and the transit time of electron motion inside the vacuum, which appear an essential limitation to the operating frequency and produced power of imitative gridded tubes. When the transit time became an appreciable part of a microwave frequency cycle, performance degenerated, forcing the designer to smaller and smaller sizes to attain higher frequency. Limitations associated with voltage and size was encountered higher frequency and higher power levels. 2) Mass change at high voltages could be fundamental to a new type of beam wave interaction. Power/ Frequency objective of $1 \mathrm{MW}$ continuous wave at $140 \mathrm{GHz}$ are being pursued [37].

The applied of new materials and processes in microwave generators, lead to the improvements large performance. For example, the implementation and availability of high thermal accessibility beryllium oxide or boron nitride has pliable signifier improvements in most continuous wave power produce traveling wave tubes (from approximately $3 \mathrm{~W}$ to $3 \mathrm{~kW}$ ). The magnetron is considered as a backbone for microwave frequencies at the ordinary microwave, it is the best economic choice for the power generation. These tubes are used in all domestic microwaves (2-3 GHz range) but in industrial ovens with output to a megawatt.

Magnetron is the main part in tubes and it is called "crossed field", this is because the main interaction depend on electron motion in electric fields which became perpendicular to one another and consequently crossed. Cathode (a cylindrical electron motive), is enclosed by anode (cylindrical structure), at high capacity and able to provide support to microwave fields. Magnets are arranged to equipping a magnetic field parallel to the axis and therefore perpendicular to the electric fields of the anode cathode [37].

Microwave Advantages [38, 39]

1) Microwave produce high power intensity, can increased output speeds and reduce cost product;

2) Microwave is compact equipment, so, it is requiring a small space or footprint. Microwave energy is controlled where it can be turned on and turned off easily;

3) Because microwave lack of high temperature heating surfaces, it reduces the product contaminate in microwave heaters, which lead to increase production run times and decrease cleaning times and chemical costs;

4) Non-contact drying technology, for example, IMS planar dryers application in the textile industry, it can reduce harm of material finish, decrease drying fatigue as well as improve quality of the product;

5) Area of greater moisture can selective absorbed microwave energy, which lead to more uniform heating as well as moisture profiles, enhanced product performance and improved yields.

6) When industry use microwave systems, it can avoid harmful gaseous by products, improved working situation and eliminating the need for environmental permits

Microwave Disadvantages:

1) Restricted transmission ability

2) Must be observed the certain topographical conditions and in certain state a special structures of erection is required

3) Long distances need relay stations.

4) Weather can be caused disruptions

\section{Harmful Effects of Microwave}

When microwave react with materials, microwave energy probably:

i) Reflected (as in metal)

ii) Transmitted (as in glass)

iii) Absorbed (as in living tissues)

The last case is the most serious result for human exposure to microwave irradiation. The person's temperature increases if the environmental temperature and humidity are so high. Hence, when whole body exposure to power densities on the order of $1-10 \mathrm{~mW} / \mathrm{cm} 2$ lead to the biological thermal stress, this depends strongly on the environmental temperature and humidity. The hyperthermia is the most authenticated harmful biological effects on human from microwave. These contain eye damage, and testis which are not able to efficiently dissipate absorbed energy which greater than $10 \mathrm{~W} / \mathrm{m} 2$. Normally, the possible health risk because of exposure to microwaves is extraordinarily dependent on the sphere strengths, frequencies and probably to exposure time $[39,40]$. 


\section{Microwave Safety:}

The common question in this section is the microwave heating is more costly than classical heating? The answer depends on its application. In several cases, microwave can be more effective $50 \%$ than classical heating, this lead to save in time, energy as well as cost.

\section{Microwave Coloration}

Microwave Dyeing:

Dyeing of linen fabric:

Many authors [41] detailed that only direct and reactive dyes have a reasonable affinity to linen fabric, which leaves behind, a lot of amount of chemicals are discharged from the cellulosic fabric dye bath. A. Nabil Ibrahim et al introduced a novel technique "free salt dyeing" of linen fabric. To achieve this, the authors treated linen fabric with different concentration of chitosan under different microwave power level for different interval time at different $\mathrm{pH}$. The treated and untreated one was dyed with direct and reactive dye by using free salt dyeing technique under microwave irradiation. The residual dye solution was reused for several times, after replenished with fresh water to preserve a constant liquor ratio, until complete dye exhaustion from the dye bath. From obtained result, the author observed that as the chitosan concentration, treated time (10-60 $\mathrm{min})$ and microwave power level (until 560 watts) increased the $\mathrm{K} / \mathrm{S}$, as well as $\mathrm{N} \%$ increased at $\mathrm{pH}=3$. Also, there was a slightly change in physical properties of treated linen fabric. The dyed treated fabric give high $\mathrm{K} / \mathrm{S}$ value than classical method (following the industry instructions), and there are no remarkable changes observed in fastness properties when applied two heating method. From the result, we can be observed that we can be reused the residual dye solution for several times to reduce the environmental pollution but it gives a different colour tons.

\section{Dyeing of wool fabric:}

Some authors [42] studied the effect of treated wool fabric with microwave irradiation at different conditions on its physical and chemical properties using different techniques, such as IR spectroscopy, X-ray diffraction pattern as well as scanning electron microscope. The result revealed that microwave irradiation significantly improved wool fabric dyeability. This may be due to the change which occurred in wool surface morphological structure when treated with microwave irradiation; this means that the barrier effect in wool dyeing was diminished. The result J. Text. Color. Polym. Sci. 16, No. 1 (2019) showed that the breaking strength of the treated wool fabrics improved with microwave irradiation as well as no significant change occurred on the chemical structure and crystallinity.

\section{Polyester dyeing:}

J. Kale Manik et al.[43] studied the solvent (DMF) pretreated of polyester fabric by using microwave oven to enhance its dyeability with commercial disperse dyestuff; the dyeing process was carried out by exposure the polyester fabric to microwave irradiation at different temperature and different interval time. The results revealed that the microwave irradiation enhanced the interaction of solvent with the polyester fabrics, solvent molecules react quickly, not only with the fibers K. Haggag et al. [47] surface but also with the internal parts. The photographs of scanning electron microscope illustrated that the structural modulation takes place which leads to producing surface roughness and gaps, consequently, this enhanced the dye uptake three times if compared to the classic methods.

While the other author [44] was cared about to a comparative study of the dyeability of polypropylene fibres with a disperse dye via microwave as well as ultrasonic energy. For this the microwave dyeing was carried out at different energy level (L, M-L, M, M-H and H) for different interval times ( 1 to $5 \mathrm{~min}$ ) while in the case of ultrasonic wave dyeing was carried at different temperature $\left(20,40,60\right.$ and $\left.80{ }^{\circ} \mathrm{C}\right)$ and for different times (1-30 $\mathrm{min})$ in the presence and absent of the carrier. The result demonstrated that microwave and ultrasonic energy dyeing gave good $\mathrm{K} / \mathrm{S}$ values, depending on microwave power level (as the power level increased the $\mathrm{K} / \mathrm{S}$ increased), ultrasonic temperature, and the addition of a carrier to the dyebath. It was observed that the optimum dyeing time was achieved after 15-20 min in the case of ultrasonic dyeing while after $5 \mathrm{~min}$ in the case of microwave dyeing. Diffusion coefficients obtained in both microwave and ultrasonic dyeing techniques without carrier were better than those obtained when using the classical technique with the carrier. The author recommended that new dyeing techniques produced higher $\mathrm{K} / \mathrm{S}$ and shorter dyeing times and therefore better economy. These advantages should be examined to determine if they are industrially applicable.

While some authors [45] were explained the reaction of the microwave with Partially Oriented Polyester yarn (PET-POY) to improve 
its structure as well as its properties which related to textile properties. They investigated the effects of exposing the PET-POY filament to microwave irradiation $(2450 \mathrm{MHz})$ for different time (15-105 sec.) on its structure and morphology, by using X-ray diffraction, birefringence, and DSC. The changes in its chemical and physical properties as tensile strength, shrinkage, and dye absorption were evaluated. They concluded that microwaves have a significant effect on crystallinity, crystal size as well as crystalline orientation. In addition, the microwave treated samples were improved in total orientation; crystal distribution became narrower and increased as compared to the control one. The result showed a significant increase in tensile strength, shrinkage and dye absorption.

Al-Mousawi et al [46] noticed that the polyester fabrics dyed with thienobenzochromene disperse dyes based on the arylazothienobenzochromene moiety, using high-temperature dyeing (HT) at $130^{\circ} \mathrm{C}$ for $60 \mathrm{~min}$ as well as microwave heating. The polyester properties in term of $\mathrm{K} / \mathrm{S}$, CIELAB values and fastness properties were evaluated. The obtained result showed that: orange to violet color shades was obtained, expressed on $\mathrm{k} / \mathrm{S}$ value and the colorimetric data microwave dyeing samples were darker, slightly less red and yellow than the classical samples, $\mathrm{k} / \mathrm{S}$ value of dyed samples by microwave irradiation was higher than the classical one due to shorter dyeing time, energy saving and better dye uptake. The fabrics dyed by both methods showed excellent fastness properties to washing and perspiration. According to the inhibition zones, Dye 6a-e showed no activities against the fungus that used in this study, while dye 6a showed strong inhibitory effects on the growth of $\mathrm{S}$. cerevisiae and dyes ${ }^{\top} \mathrm{a},{ }^{\top} \mathrm{c}$ and ${ }^{\top} \mathrm{e}$ revealed higher activities against the Gram-negative than those recorded for the Gram-positive bacteria.

Likewise, E Öner et al. dyed[47] poly(butylene terephthalate) fabrics with different disperse dyestuff in microwave dielectric heating and compered with the samples dyed by using the classic one, to determine the possibility of using microwave oven to increase the dyeability of these fibre in shorter processing times and to obtain enable appropriate wet fastness. For this, the samples were dyed with different disperse dyes at $98^{\circ} \mathrm{C}$ with or without microwave dielectric heating. The obtained results showed that microwave has a significant effect the colouristic properties, color fastness as well as tensile strength. The author recommended that microwave dielectric heating is considered as a tool for 'green chemistry' which provides many advantages over classical heating without any deterioration in the dyed fabric properties.

\section{Nylon Dyeing:}

K. Haggag et al. [48] detailed the using of microwave technology for dyeing of nylon 66 fabric by disperse dyes. Many parameters which affected on the dyeing process namely dyeing time, dye concentration, microwave power level (watt), as well as liquor ratio, were studied. The result revealed that the microwave technique has many advantages: i) the dyeing time does not exceed further than five minutes, ii) microwave power level does not exceed 200 watts, iii) microwave save about 40 minutes, iv) un-carrier dyeing and no using of dispersing agent. The Author recommended that microwave technique can save time, energy as well as industrial money.

\section{Extraction of Natural colourants:}

Sindra L Summoogum-Utchanah et al [49] explained a comparative study between the extraction of betalains and curcuminoids from the two plants by using classical magnetic stirring (MS) and microwave-assisted extraction techniques (MAE). The results showed that MAE is an efficient process for isolation of dyes as it reduces the extraction time drastically to the classical system. The variation of the solvent mixture, agitation of the magnetic stirrer (MS), microwave power level, solid to the solvent ratio (SSR) and particle size of the plant were studied to determine the highest extraction yield of betalains and curcuminoids. The analysis revealed that the optimum conditions were obtained at $50 \%$ aqueous ethanol, agitation speed of $160 \mathrm{rpm}$, microwave power level 320 watt, particle size $0.45 \mathrm{~mm}$, and SSR of $1 / 35$. Beside, Peleg's and Elovich's mathematical models were evaluated and represent the kinetics of natural dyes extraction. Peleg's kinetic model was mostly valid in describing the extraction kinetics, particularly to MS while Elovich kinetic model fitted the experimental data of MAE more accurately. It could be ultimately deduced that the use of MAE for the leaching of pigment solutes, is considered as an available technique for enhancing a slow process and most essentially requiring less energy consumption with high extract quality.

Some authors focused on the applied of nanotechnology (microwave and plasma treatment) to improve dyeability of polyester J. Text. Color. Polym. Sci. 16, No. 1 (2019) 
fabric, carrierless (eliminate or reduce the use of chemicals) as well as its interaction with silver nanoparticles to improve its antibacterial activity [50]. The dyeing process was carried out in microwave at different condition namely power level and time, while plasma treatment was carried out at different time, flow rate and different gas type. The obtained result showed that microwave irradiation enhanced the dyeability of polyester fabric without using carrier (free carrier dyeing). While on the other side, the authors found that plasma treatment enhanced dyeability of polyester fabric, this may be attributed to increase of polar groups which enhance the fabric wettability thus improve the dye absorption. The SEM image showed that there is an increase in surface roughness and voids which lead to improving dye penetration. The author recommended that microwave, plasma, and nanotechnology are considered as green technology for functionalization of polyester fabrics which refers to improvement fabric dyeability, interaction with silver nanoparticles to improve antibacterial activity to the fabrics. These recent technologies are economically feasible, secure, and achieve superiority over other traditional methods.

E.M.El-Khatib et al. [51] have investigated the effect of microwave heating on extraction of natural dyes from Saffron (Crocus sativus) vis Classical method. Many parameter which effect on dyeing process as (dye extracted quantity, dye concentration, $\mathrm{pH}$, temperature and duration of dyeing bath processes) were studied. In this study, the authors were used chitosan as eco-friendly for pretreatment instead of chemical mordant for dyed silk fabric. According to dye extraction as well as $\mathrm{K} / \mathrm{S}$, the result revealed that microwave heating show many advantages than the classical method: (i) higher $\mathrm{K} / \mathrm{S}$ value, (ii) saving time and reduce energy consumption, (iii) higher dye uptake, (iv) show good overall fastness properties. The authors recommended that, it is necessary to promote non-polluting natural dyes, which involve inexpensive equipment and small-scale operations. This equipment shows the feasibility of providing high-quality natural dyes extracted from plants, improving environment, and giving opportunities to the fabric industry to catch up with the current consumer trends towards more aesthetic fabrics with natural products.

While M. Hussaan et al [52] reported that microwave-assisted enhancement of milkweed (Calotropis procera L.) leaves as an eco-friendly source of natural colorants and its application on dyed cotton fabrics assisted with biochemical mordants. The parameters which effect on dye extraction namely $\mathrm{pH}$ mediums ((alkali and aqueous) and exposure time to microwave irradiation were studied. The factors which effect on $\mathrm{K} / \mathrm{S}$ (colour strength) such as $\mathrm{NaCL}$ (sodium chloride) concentration and heating system were also evaluated. The results illustrated that the using of microwave irradiation was enhanced the dye extraction for four minutes in alkaline medium if compared to aqueous medium $>$ Dyeing process was carried out by exhaustion process at $55^{\circ} \mathrm{C}$ in the presence of $3 \mathrm{~g} / 100 \mathrm{ml} \mathrm{NaCL}$. Using $9 \%$ iron as a chemical mordant for pre- and post-mordanting. give the maximum value of $\mathrm{K} / \mathrm{S}$, while the premordanting by using $5 \%$ of bio-mordant extracted from nilotica bark give the higher value of $\mathrm{K} / \mathrm{S}$. However, the best $\mathrm{K} / \mathrm{S}$ was obtained with $9 \% \mathrm{C}$. longa tuber extract as post-mordant

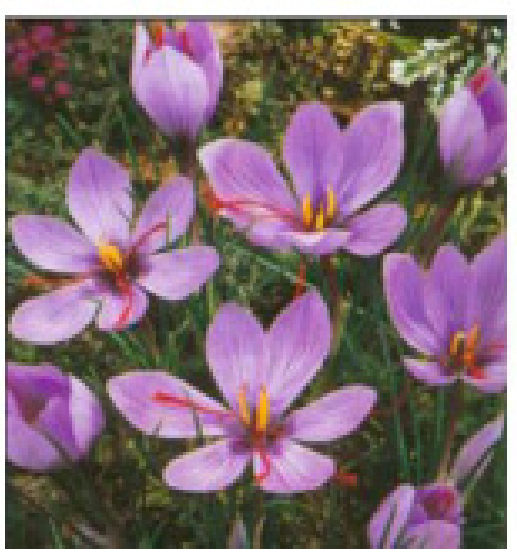

Saffron plant

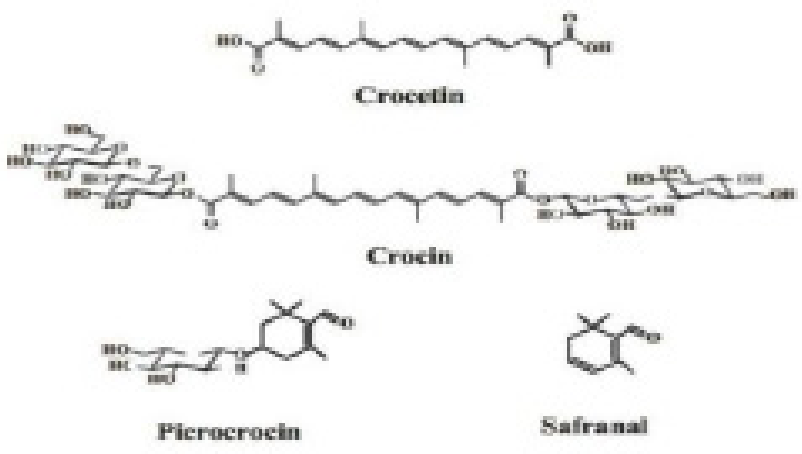

Structure of the chemical constituent of saffron 


\section{Microwave pretreated}

Many Authors [53] studied the effect of pretreated wool fabric with microwave irradiation then dyed with Lanasol reactive dye as well as Palatin 1:1 metal complex dye by the classical heating method. The result showed the pretreated wool samples by using microwave heating were achieved a higher dye uptake and there is an increase in diffusion coefficient. The microwave pretreated samples have a slightly damaging effect on the surface scale-like structure of wool which leads to reducing the concentration of (SS) bonds in keratin. This surface damage will improve the absorption of dye molecules by the wool fibres during dyeing and the diffusion of dye molecules into the fabrics.

On the other hand, O. G. Allam et al. [54] proved that that the Synergistic effect of alkali treatment using microwave heating enhances the dyeability of dyed wool/polyester blend fabric with acid and reactive dyestuffs in one step. Many parameters namely treatment mode, alkali concentration, treatment and dying time were studied to determine the optimum condition for treatment and dyeing of polyester/wool blend fabric. The effect of alkali and microwave irradiation on morphological structures of treated fabric and compared it with the similar samples treated by classical technique. From the result, we observed that (i) the alkali $(\mathrm{KOH})$ treated fabric $4 \mathrm{~g} / \mathrm{L}$ in microwave irradiation at power level $90 \%$ for 2 min maintained the morphological structure of treated fabric without damage, (ii) $\mathrm{K} / \mathrm{S}$ was three times higher than the fabric treated when using classical technique. (iii) Microwave heating increases the swelling degree of PES/W in a short time while classical heating didn't affect the fabric swelling, (iv) Microwave energy reduce time to achievement required balance that can give reasonable $\mathrm{K} / \mathrm{S}$ without deterioration, (v) The classical dyeing need more than $30 \mathrm{~min}$ to reach the equilibrium state while microwave need 20 min only, (vi) there is no any distinguishing increase or decrease in the tensile strength and elongation $\%$ of treated fabrics when using microwave irradiation. The TEM image showed that the microwave treatment didn't causes any damage on the surface scale-like structure of the polyester/wool blend fiber and relatively maintains the morphological structure of treated fabrics without deterioration, while the scale-like of the PES/W fiber was deteriorated under the effect of thermal heating.

\section{Microwave printing:}

K.A. Ahmed et al [55] reported that microwave irradiation technique is an efficient process for preparing fluorescent dyes. This study was concerning on preparation and evaluation for coumarin based on chromophores containing chalcone moiety. Element analysis, IR, 1H-NMR as well as mass spectra were investigated to study the structure of synthesized dyes. The result showed that there is a shift towards the red-shift according to strength of electron donating and conjugation length. Strong bathochromic shift occurred by replacement of carbazolyl donor with a hetaryl or substituted hetaryl group in the coumarinyl-based chromophores. The prepared fluorescent colors were used in textile printing of polyester and polyamide fabrics by using flat screen technique.

The other author [56] reported that the microwave heating can be used to synthesize aqueous binders for pigment printing of polyester fabrics. A different of new prepared polyurethane polymer has been utilized as a binder for polyester fabric printing by using screen technique, thermos fixation and radiation curing (UV\& microwave) fixation modes were used for pigment fixation meanwhile polymerization process for binder. This research deals with the study the effect of change in temperature of thermos fixation and curing time of microwave as well as UV with the content of prepared binders in printing paste on the color strength, and prints fastness properties. It was found that the prepared polyurethane acrylate binders could be successfully used for pigment printing of polyester fabric when using three fixation modes and the color strength value was higher to those obtained using selected commercial binders. The fastness properties of printed samples using microwave curing technique ranged from good to very good and from moderate to good in case of commercial one.

Abdel-Thalouth et al [57] reported that microwave-assisted textile printing of cellulosic fabrics. The author used two different commercial reactive dyestuffs to print cellulose fabric via screen printing technique. The printed fabrics were exposure to microwave irradiation at different power level (400-800 watt) for different period of time (1-9 $\mathrm{min}$ ) and different temperature $\left(50-150^{\circ} \mathrm{C}\right)$. Another, printed samples were drying and fixed according to the classical thermo-fixation techniques recommended for each reactive dye used. From the obtained data 
it is clear that as the exposure time, microwave power level as well as temperature increase the $\mathrm{K} / \mathrm{S}$ increase. The theory of microwave heating is converting radiation waves into heat, this depend on the dipolar molecules $\left(\mathrm{H}_{2} \mathrm{O}\right)$, an experience was made to save same $\mathrm{H}_{2} \mathrm{O}$ molecules and decrease its evaporation from the printed film, this was achieved by covering the printed sample with a paper and/or plastic sheet. The author also was found that the $\mathrm{K} / \mathrm{S}$ of the printed and microwave fixed fabrics follows this order samples covered with plastic sheet $>$ samples covered with paper sheet $>$ uncovered samples.

Likewise, in the other research these authors explained that Microwave was assisted fixation of pigment prints on cotton fabrics via flat screen technique [58]. After printed, the printing samples were exposed to microwave irradiation for different time (min) and different power level (watt). To comparison the other sample were printed under the same condition and fixed by using classical technique. According to $\mathrm{K} / \mathrm{S}$ data, the authors were found that the printed sample fixed via microwave irradiation has higher $\mathrm{K} / \mathrm{S}$ value than those were fixed by classical one, as the time of exposer to microwave irradiation and microwave power level increased the $\mathrm{K} / \mathrm{S}$ value increased. They also found that the covering sample with paper sheet sheets led to a significant increase in $\mathrm{K} / \mathrm{S}$ value than the uncovered sample and follows the following order:

Uncovered sample $<$ paper sheet covered sample $<$ plastic sheet covered sample

From the obtained result reveals that the K/S of printed sample improved when use nano- size pigment. The authors recommended that to achieve the maximum $\mathrm{K} / \mathrm{S}$ value we must use nano size pigment printing dye and exposer the printed fabric to microwave irradiation for $7 \mathrm{~min}$ at 800 watt.

Because the limited area of natural resources as well as increasing environmental legislation for eco-friendly and sustainable technologies, It is expected that in the next few decades, there are an increase on using of renewable feedstock in the textile industry. This study focused [59] on to introduce a simple technique for alkyd resins synthesis from renewable resource (sunflower and soybean oils) under the influence of microwave irradiation, and its application on textile pigment printing. The characteristic of prepared binder namely Iodine value (Iv), Acid value (AV), Water absorbency, weight loss, Glass transition temperature (Tg), Rheological properties, IR, scanning electron microscope and TEM were characterized. Color measurements, roughness measurement as well as fastness properties were evaluated. The results revealed that as the reaction temperature increase the $\mathrm{AV}$ as well as IV decreased. AV, IV and the reaction time decrease as the catalyst concentration increased. According to $\mathrm{AV}$ and IV value, as microwave power increased, the reaction time decreased. The results declared that the prepared alkyd samples are hydrophobic nature and the weight loss of the prepared binder is much less than the commercial ones. According to TEM photographic, the particle size of prepared binder ranged from 20-200 $\mathrm{nm}$ which improve the adhesive properties and crosslinking of the prepared binders, thus color strength and fastness properties of the printed fabrics.

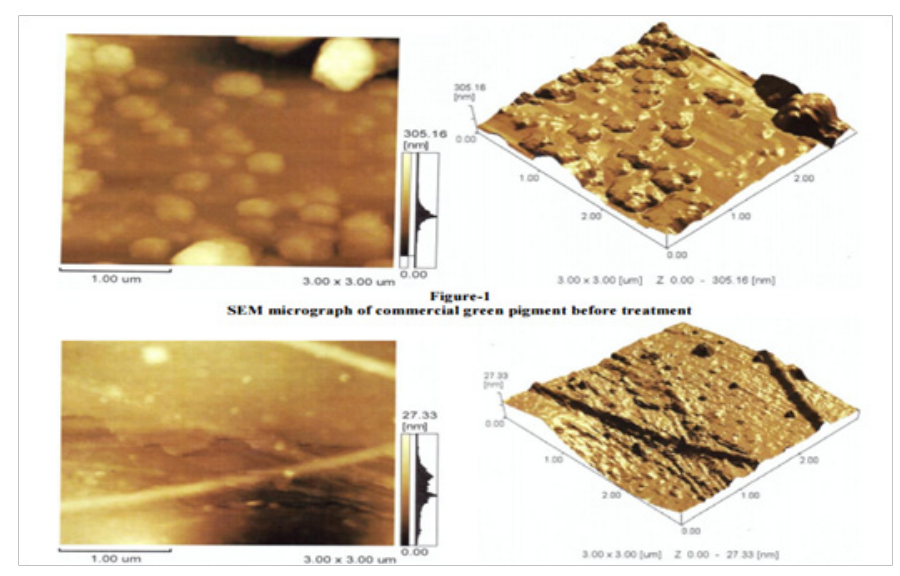

SEM micrograph of commercial green pigment after treatment 


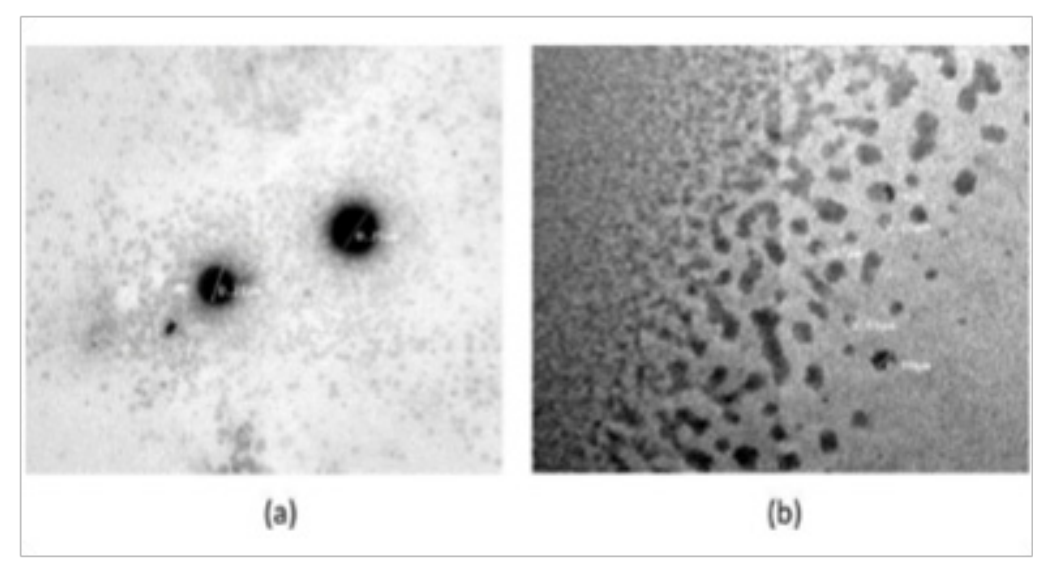

TEM image of prepared binder from (a) sunflower oil, (b) soybean oil

Microwave synthesis:

A. D. Sagar et al. [60] reported the prepared of carboxymethyl starch by modification or derivatization of insoluble wheat starch with $\mathrm{ClCH}_{2} \mathrm{CO}_{2} \mathrm{H}$ (monochloro acetic acid) in presence of $\mathrm{NaOH}$ (sodium hydroxide) under different conditions using microwave irradiation to improve the natural thickener for textile printing (scheme 1). The characterization of carboxymethylation was evaluated according to degree substitution degree (DS), active content (A.C.) as well as alkaline fluidity (A.F.). The CMS of different substitution degrees were prepared by changing the reactants ratio and/or the reaction time. The result showed that a great enhanced in D.S. by increasing the reaction time, as the $\mathrm{ClCH}_{2} \mathrm{CO}_{2} \mathrm{H}$ acid and $\mathrm{NaOH}$ concentration increased, D.S. also increased. The author also reported that A.F. increases as a decrease in A.C. IPA or IPA : Water mixture, isopropanol : water [80:20] considers the most favorable medium for the carboxymethylation reaction to prepare CMS with appropriate D.S. and fluidity. Prepared CMS could be very good thickener in textile printing paste with environmentally renewable and partially or fully alternating material for sodium alginate.

Some author in literature [61] described a simple and highly efficient procedure for the solvent free synthetic derivatives of 3-(4-Ethylbenzyl)-1-(4methoxybenzyl)- 6-(methylthio)-1,3,5-triazine$2,4(1 \mathrm{H}, 3 \mathrm{H})$-dione under microwave irradiation at
$400 \mathrm{~W}$ using household microwave. They reported that the major advantage in solvent free conditions which gives economical synthetic approach is a high retrieval of unreacted raw materials. So, the author designed solvent free microwave assisted synthesis triazine derivatives by substituting "-SMe" with primary amine. The obtained results illustrated that the complete conversion of starting materials to product took about 5 min when using microwave irradiation, instead of 8 hours when using classical heating. Author recommended that the microwave irradiation has many advantage, it reduce the reaction time, avoids other unwanted side reactions, experimental protocol is easily accessible on milligram to gram scale and also environmentally safe.

The other study focused on to save water, chemicals and reduced the quantities of effluent discharged during the dyeing of polyester fibers [62]. Here the authors reported that the feasibility to use microwave irradiation to prepare a series of4-hydroxyphenylazopyrazolop yrimidine disperse dyes via one-pot reactions of p-hydroxyphenylhydrazone, hydrazine hydrate, and acetylacetone or enaminones. Then use this prepare dyes to dyeing of polyester fabrics at $130{ }^{\circ} \mathrm{C}$ for $60 \mathrm{~min}$, under pressure in a focused microwave oven. After each dyeing cycle, the residual dyebath was spectrophotometrically analyzed and readjusted $\mathrm{pH}$ for a reused of this residual solution for dyeing another polyester fabric instead of discharging the dyebath at the

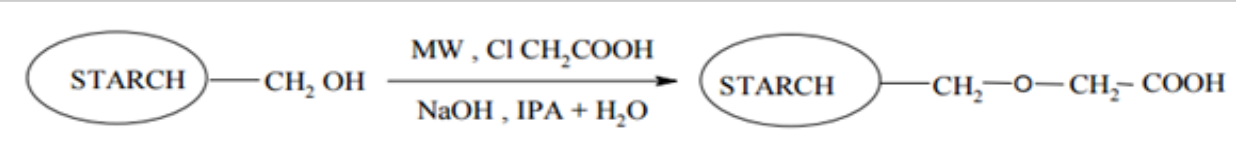

Scheme 1 
end of every dyeing process. The characterization of dyed fabric was evaluated after each recycles depending on $\mathrm{K} / \mathrm{S}$ value as well as fastness properties. The obtained data illustrated that the feasibility to reuse the residual dye bath with a good light fastness and excellent fastness to washing and perspiration. The biological activity of the manufactured dyes against Gram positive, Gram negative bacteria and yeast showed strong activities, with significant inhibition zones $>10$ $\mathrm{mm}$, against Gram positive bacteria, it worth saying that all tested compounds self-conscious the growth of the Candidia albicans

The synthesis of 2-amino- and 2- hydroxy6-substituted-5-arylazonicotinates dyes was reported [63]. This study focused on to use a new strategy for the synthesis of these disperse dyes in a good yields by condensation of arylhydrazonals with ethyl cyanoacetate using microwave irradiation as a heating source to improve and facilitate the synthesis process. The result showed that the formation of 2-aminoarylazonicotinate disperse dye 6 , as a result of the interaction between a mixture of the arylhydrazonal $2 \mathrm{a}$ and ethyl cyanoacetate in presence of overabundant of ammonium acetate by using microwave irradiation at $180{ }^{\circ} \mathrm{C}$ for $30 \mathrm{sec}$. The possibility of using these prepared disperse dye to dye PET fabric was studied. The result revealed that the polyester fabric display yellowish-orange to dark brown hues. The dyed fabrics showed an excellent washing and perspiration fastness but moderate light fastness. The synthesized disperse dyes showed strong positive antimicrobial activities and strong ability to inhibit the growth of Candida albicans.

N.S. Elshemy et al. [64] studied the possibility of using microwave irradiation to one pot synthesis of $\mathrm{TiO}_{2}$ nano particles within a couple of minutes. To achieve this, $\mathrm{TiO}_{2}$ nano particle was done by Sol-Gel technique by following two different heating sources (microwave and classical heating), treated cotton fabric with different concentration of chitosan (1-2\%) dissolve in distilled water and $2 \%$ acetic acid for 60 minutes at $60^{\circ} \mathrm{C}$. The treated chitosan fabrics were then treated with different concentration (0.5-2\%) of the prepared $\mathrm{TiO}_{2}$ nanoparticles before and after dyeing with two different acid dyes. The result revealed that it is possible to prepare $\mathrm{TiO}_{2}$ in nano form by using microwave heating and it can be achieved in $16 \mathrm{~min}(8 \mathrm{~min}$ for drying and $8 \mathrm{~min}$ for calcination) at $90 \%$ power level instead of 8 hours using classical method<smiles></smiles>

Acid dye 1<smiles></smiles>

Acid dye 2
According to TEM photograph the $\mathrm{TiO}_{2} \mathrm{NPs}$ size that prepared by using classical technique and/or microwave irradiation is smaller than the commercial one, we can also notice that the $\mathrm{TiO}_{2}$ NPs that prepared by using microwave irradiation is smaller than that prepared by the classical one; this may be attributed to microwave irradiation. The materials can absorb microwave energy specifically and inside and convert it into heat. This prompts points of interest, for example, quick, controlled, specific and uniform heating in a short time.

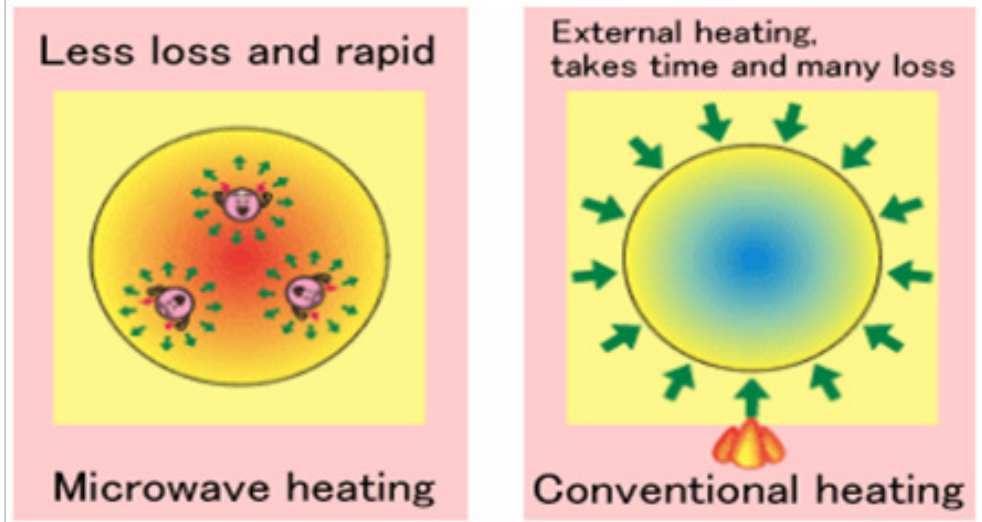


The obtained result proved that the antibacterial activity of pre-treated fabric with TiO2 NPs (before and after dyeing) that prepared by using microwave heating was greater than the prepared by using the classical heating. All treated samples were exhibited an excellent color fastness to washing, rubbing and light fastness. It is worthy to say that it exhibited poor color fastness to respiration fastness.

\section{Dye removal:}

B.I. XIAOYI [65] were detailed the feasibility of using microwave to removal of remazol golden yellow dye by enhancing chlorine dioxide $\left(\mathrm{ClO}_{2}\right)$ catalytic oxidation process. In this research, the author was used $\mathrm{CuOn}-\mathrm{La}_{2} \mathrm{O}_{3} /-\gamma-\mathrm{Al}_{2} \mathrm{O}_{3}$ as a catalyst, and evaluated different parameters such as, $\mathrm{ClO}_{2}$ content, catalyst content as well as $\mathrm{pH}$. The result illustrated that microwave irradiation has efficient technique in catalytic oxidation process to degrade remazol golden yellow dye with reducing oxidant content and reaction time at wide $\mathrm{pH}$ if compared with classical wet catalytic oxidation. It was found that microwave color removal efficiency approached 94.03\%, this equivalent to $67.92 \%$ of total organic carbon removal efficiency. Also the obtained data showed the fluorescence intensity in microwave enhanced $\mathrm{ClO} 2$ catalytic oxidation system was about 500 a.u. this improve that there was much hydroxyl radical produced. The author reported that microwave irradiation enhanced $\mathrm{ClO} 2$ catalytic oxidation system which leads to significantly enhance the degradation efficiency. Microwave provides an effective technology for dye wastewater treatment.

YJ Cai et al. [66] showed the possibility of using classical UV irradiation and microwave electrodeless UV irradiation in degradation of reactive brilliant red $\mathrm{X}-3 \mathrm{~B}$ solution. From the obtained result, it can be observed that the microwave electrodeless UV irradiation is more effective in degradation of reactive brilliant red $\mathrm{X}-3 \mathrm{~B}$ than classical UV irradiation. Therefore, microwave electrodeless UV light had substantial role in increasing the degradation efficiency. The color removal was nearly $100 \%$ after $110 \mathrm{~min}$ while TOC removal was up to $67 \%$. Also, it was observed that the degradation of the molecular conjugation system a fast process, while the degradation of the benzene and naphthalene rings was a relatively slow process. Through the degradation, a great amount of organic acids were formed and at the end of reaction the most compounds were oxidized to carbon dioxide $\left(\mathrm{CO}_{2}\right)$ and water $\left(\mathrm{H}_{2} \mathrm{O}\right)$ which lead to decrease/increase in $\mathrm{pH}$ pattern. As the reaction time increase, the degradation of the dye solution increased. The inorganic anions analysis demonstrated that the majority of the nitrogen $(\mathrm{N})$, Cholor $(\mathrm{Cl})$, and Sulphur (S) elements from reactive brilliant red $\mathrm{X}-3 \mathrm{~B}$ were still linked to organic molecules. According to a preliminary cost calculation, the operational cost of microwave electrodeless UV irradiation processes was cost-effective in contrast with biochemistry treatment. Of course the degradation capacity would be increased if employed more electrodeless UV lamps while the treatment time would be decrease, but the treatment cost would be still acceptable for a dyeing manufactory.

\section{Outlook}

1. Microwave technology is starting to get the attention due to its smart functions in producing new materials. Microwave organic reactions can accelerate a great number of chemical processes in an eco-friendly way, especially, it decrease the reaction time and energy that are run for a long time at high temperatures under classical techniques, this makes dyeing easily to cover the request of the high demand growing market.

2. In addition, the demand for eco-friendly textile production techniques will support more studies in the usage of the microwave in industrial scale, which help in reducing the pollution emitted from dye absorption and dye fixation as well as improving them.

3. Last but not least, the study of using the microwave in dyeing will get more attention to make it possible to use in small-scale enterprises.

4. Microwave with or without the catalyst is a simple, economic, efficient, precise and ecofriendly way to detox water.

\section{$\underline{\text { References }}$}

1. K Hunger, editor, Industrial dyes: chemistry, properties, applications, John Wiley \& Sons; ( 2007)

2. A. Bafana, S.S. Devi, and T. Chakrabarti, Azo dyes: past, present and the future, Environ. Rev., 19 350371 (2011) .

3. M.I. Greenberg, Occupational, industrial, and environmental toxicology, Elsevier Health Sciences, (2003).

J. Text. Color. Polym. Sci. 16, No. 1 (2019) 
4. SB. Moore, LW. Ausley, Systems thinking and green chemistry in the textile industry: concepts, technologies and benefits, JOCP, 12, 585-601 (2004).

5. R. Kant, Textile dyeing industry an environmental hazard, NSCI, 4, 22 (2012).

6. Ram. Nidumolu, , K. Coimbatore Prahalad, and R. Madhavan Rangaswami, Why sustainability is now the key driver of innovation, HBR, 87, 56-64 (2009)

7. M. Shahid, F. Mohammad, Recent advancements in natural dye applications: a review. JOCP, 53, 310331 (2013).

8. AK. Verma, RR. Dash, P. Bhunia, A review on chemical coagulation/ flocculation technologies for removal of colour from textile wastewaters, $J$. Environ. Manage, 93, 154-68 (2012).

9. I. Holme, Innovative technologies for high performance textiles, COLOR TECHNOL, 123, 59-73 (2007).

10. J.H. Clark, R. Luque, and A.S. Matharu, Green chemistry, biofuels, and biorefinery, Annu. Rev. Chem. Biomol. Eng. Published by: Annual Reviews, 3, 183-207 (2012)

11. NS. Ahmed, RM. El-Shishtawy, The use of new technologies in coloration of textile fibers, $\mathrm{J}$ MATER SCI. 45, 1143-53. (2010)

12. F. Mohammad, Emerging green technologies and environment friendly products for sustainable textiles, In Roadmap to sustainable textiles and clothing, , 63-82 (2014).

13. R. Atav, The use of new technologies in dyeing of proteinous fibers, INTECH Open Access Publisher; (2013).

14. HJ. Kitchen, SR. Vallance, JL. Kennedy, N. TapiaRuiz, L. Carassiti, A. Harrison, AG. Whittaker, TD. Drysdale, SW. Kingman and DH. Gregory, Modern microwave methods in solid-state inorganic materials chemistry: From fundamentals to manufacturing, Chem. Rev., 14, 1170-206 (2013).

15. R. Rosa, P. Veronesi and C. Leonelli, A review on combustion synthesis intensification by means of microwave energy, CHEM ENG PROCESS, 71, 2-18 (2013).

16. D.E. Clark, and W.H. Sutton, Microwave processing of materials, ANRMS, 26, 299-331 (1996).

17. D.E. Clark, F.D. Gac, and W.H. Sutton, Microwaves: theory and application in materials processing, ceramic transactions, 21, Westerville, J Am Ceram Soc, 451-458 (1998)

J. Text. Color. Polym. Sci. 16, No. 1 (2019)
18. M.A. Herrero, J.M. Kremsner and C.O. Kappe, Nonthermal microwave effects revisited: on the importance of internal temperature monitoring and agitation in microwave chemistry, $\mathrm{Org}$. Chem., 73, 36-47 (2008)

19. C. Zhang, L. Liao and S. Gong, Recent developments in microwave-assisted polymerization with a focus on ring-opening polymerization, Green Chem, 9, 303-14 (2007).

20. S. Mallakpour and Z. Rafiee, Application of microwave-assisted reactions in step-growth polymerization: a review, Iran Polymer J, 17, $907-$ 35 (2008).

21. R. Hoogenboom and US. Schubert, Microwaveassisted polymer synthesis recent developments in a rapidly expanding field of research, Macromol Rapid Commun, 28, 368-86 (2007).

22. J. Xia, H. Li, Z. Luo, H. Shi, K. Wang, H. Shu and Y. Yan, Microwave-assisted synthesis of flowerlike and leaf-like $\mathrm{CuO}$ nanostructures via room temperature ionic liquids, J Phys Chem Solids, 70, 1461-4 (2009).

23. RE. Morris, Ionic liquids and microwaves-making zeolites for emerging applications, Angew Chem Int Ed, 47, 442-4 (2008).

24. CO. Kappe, Controlled microwave heating in modern organic synthesis, Angew Chem Int Ed, 43, 6250-84 (2004)

25. SJ. Raff, Microwave system engineering principles, Elsevier; (2013).

26. C. Bramsiepe, S. Sievers, T. Seifert, GD. Stefanidis, DG. Vlachos, H. Schnitzer, B. Muster, C. Brunner, JP. Sanders, ME. Bruins and G. Schembecker, Low-cost small scale processing technologies for production applications in various environmentsMass produced factories, Chem. Eng. Process: Process Intensification; 51, $32-52$ (2012).

27. B.G. McConnell, A coupled heat transfer and electromagnetic model for simulating microwave heating of thin dielectric materials in a resonant cavity (Doctoral dissertation, Virginia Tech). (1999)

28. R.J. Giguere, Microwave-assisted organic synthesis, In MRS Proceedings, 269, 387. Cambridge University Press (1992).

29. V. Polshettiwar, and R.S.Varma, Microwaveassisted organic synthesis and transformations using benign reaction media, Acc. Chem. Res., 41, 629-639 (2008). 
30. J. Benford, JA. Swegle, and E. Schamiloglu, High power microwaves, CRC Press; (2015).

31. D. Bogdal, Microwave-Assisted Organic Synthesis, One Hundred Reaction Procedures, Elsevier. Amsterdam, (2005).

32. A.C. Metaxas and R.J. Meredith, Industrial Microwave Heating, Peter Peregrinus Ltd, London, UK (1983).

33. B.L. Hayes, Microwave synthesis: chemistry at the speed of light, Cem Corporation (2002).

34. CO. Kappe, Controlled microwave heating in modern organic synthesis. Angew. Chem. Int. Ed., 43, 6250-84 (2004).

35. P. LidstrUm and J. P. Tierney, Microwave-Assisted Organic Synthesis, Blackwell, Oxford, , 6250-6284 (2004).

36. K. Haggage, A. Ragheb, S. H. Nassar, M. Hashem, H. El Sayed and I. Abd El - Thalouth, Microwave irradiation and its application in textile industry", Science Publishing Group, First Edition, (2014).

37. National Academy Press, Microwave Processing of Materials, National Academy, Washington D.C. (1994).

38. M. Oghbaei and O. Mirzaee, Microwave versus conventional sintering: a review of fundamentals, advantages and applications, J. Alloys Compd., 494, 175-89 (2010).

39. S. Al-Assafi and D.E. Clark, Microwave joining of ceramics: A study on joining alumina both directly and with alumina gel, InMRS Proceedings, Cambridge University Press, 269, 335. (1992)

40. www.industrialmicrowave.com.

41. N.A. Ibrahim, W.A. ElSayed, and N.A. Ameen, A novel technique to minimise energy and pollution in the dyeing of linen fabric, COLOR TECHNOL, 126, 289-295 (2010).

42. X. Zhao, and J.X. He, Improvement in Dyeability of Wool Fabric By Microwave Treatment, IJFTR, 36, 58-62. (2011)

43. M.J. Kale, and N.V. Bhat, Effect of microwave pretreatment on the dyeing behaviour of polyester fabric, Coloration Technology, 127, 365-71. (2011)

44. N. S. Elshemy*, M. H. Elshakankery, S. M. Shahien, K. Haggag and H. ElSayed, Kinetic Investigations on Dyeing of Different Polyester Fabrics Using Microwave Irradiation, Egypt. J. Chem., , 79 -88 (2017).
45. E.A. Yigit, and M. Teker, Disperse dyeability of polypropylene fibres via microwave and ultrasonic energy, Polym. Polym. Compos., 19, 711(2011),

46. N.V. Bhat and M.J. Kale, Interaction of microwave radiation with polyester yarn to enhance its textile properties, Fibers Polym., 13 936-42 (2012);.

47. S.M. Al-Mousawi, M.A. El-Apasery, and M.H. Elnagdi, Microwave assisted dyeing of polyester fabrics with disperse dyes, Molecules, 18, 1103311043 (2013).

48. K. Haggag, H.L. Hanna, B.M. Youssef, N.S. ElShimy, Dyeing Polyester With Microwave Heating Using Disperse Dyestuffs, Am Dyest Rep, 84(3):22

(Received 22/2/2019; accepted $23 / 4 / 2019)$ 


\section{اتجاه جديد في تلوين المنسوجات باستخدام إثعاع الميكروويف}

نجلاء الثيمي و كريمة حجاج

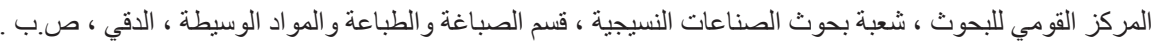

12622 ، الجيزة ، مصر لإحر

نحتاج إلى تقنيات تصنيع جديدة إذا أردنا تلبية متطلبات جيل جديد من المستهلكين. تقنيات الميكروويف تسهل هذا التقييم ، في هذه المقالة نستكثف كيف تعمل تقنية الموجات الاقيقة على مساعدة كل قطاع في تلوين النسيج.

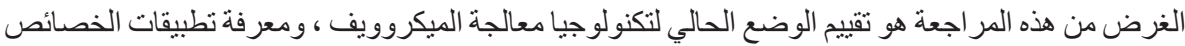

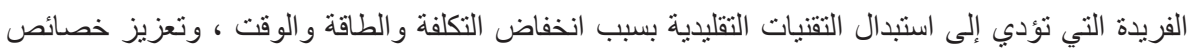

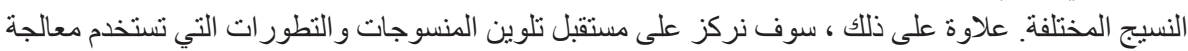

$$
\text { الميكروويف }
$$

